\title{
Từ vụ kiện Apple Inc. làm chậm iPhone ở Việt Nam, Bàn về xu hướng khởi kiện tập thể trong giải quyết tranh chấp tiêu dùng
}

\author{
Phan Thị Thanh Thủy* \\ Khoa Luật, Đại học Quốc gia Hà Nội, 144 Xuân Thủy, Cầu Giấy, Hà Nội, Việt Nam \\ Ngày nhận 08 tháng 5 năm 2018 \\ Chỉnh sửa ngày 19 tháng 6 năm 2018; Chấp nhận đăng ngày 21 tháng 6 năm 2018
}

\begin{abstract}
Tóm tắt: Ngày 10/1/2018 hai luật sư Việt Nam đại diện cho một số lượng lớn người tiêu dùng trên cả nước khởi kiện Apple Inc. ra Tòa án nhân dân Thành phố Hồ Chí Minh vì lý do tập đoàn này vi phạm trách nhiệm của nhà sản xuất gây thiệt hại cho người sử dụng iPhone các phiên bản cũ ở Việt Nam. Vụ kiện này đã nhanh chóng thu hút được sự quan tâm của giới hành nghề luật, các nhà nghiên cứu và dư luận xã hội. Bài viết này sẽ phân tích và chỉ ra các thách thức pháp lý mà vụ kiện đặt ra đối với hệ thống tòa án và xu hướng tất yếu của quy trình khởi kiện tập thể trong luật tố tụng dân sự Việt Nam.
\end{abstract}

Tù khóa: Người tiêu dùng, khởi kiện, kiện tập thể, iPhone, Apple, Việt Nam.

\section{Bối cảnh vụ kiện Apple Inc. ở Việt Nam}

Apple Inc.là một tập đoàn công nghệ máy tính của Mỹ có trụ sở chính đặt tại Cupertino, California (gọi tắt là Apple) là nơi sản xuất và phân phối những sản phẩm công nghệ điện tử chất lượng cao, trong đó có điện thoại thông minh iPhone. Từ tháng 12/2017 đến nay Apple đang phải đối mặt với những bê bối pháp lý ở diện rộng chưa từng gặp. Sự việc bắt đầu khi một học sinh trung học Mỹ, phản ánh trên mạng xã hội Reddid ngày 9/12/2017 rằng điện thoại iPhone $6 \mathrm{~s}$ của cậu bị chậm lại sau khi cập nhật

\footnotetext{
* ĐT.: 84-983807028.

Email: thuyptt@vnu.edu.vn

https://doi.org/10.25073/2588-1167/vnuls.4148
}

hệ điều hành, nhưng sau khi được thay pin mới tốc độ của máy đã được cải thiện. Lời phàn nàn này đã nhanh chóng nhận được các ý kiến đồng tình của đông đảo người dùng iPhone các phiên bản 5,6 và 7 (đời cũ) và sau đó lan rộng trên các trang mạng xã hội và truyền thông [1]. Trước thái độ giận dữ của người dùng, ngày 28/12/2017 Apple đã đăng một thông cáo chính thức trên website của hãng, thừa nhận có can thiệp làm giảm hiệu năng trên iPhone 6 (bao gồm các phiên bản $\mathrm{SE}, 6 \mathrm{~s}$ và 6 Plus) có pin suy thoái thông qua bản cập nhật iOS 10.2.1 phát hành vào tháng $2 / 2017$ với lý do tránh việc tự động tắt nguồn trong tình trạng lượng pin hoạt động ở mức thấp hoặc tuổi thọ của pin iPhone quá cao. Apple cũng đã xin lồi người dùng và cam kết sẽ giảm giá pin thay mới, từ 79 đô la 
Mỹ xuống còn 29 đô la Mỹ, cho các máy phiên bản iPhone 6 và iPhone 7 bao gồm $7 \mathrm{~s}$ và 7 plus có cập nhật hệ điều hành iOS 11.2 [2] . Trái với mong đợi xoa dịu tâm lý người dùng của Apple, thông cáo này đã gây ra một làn sóng phản đối trong cộng đồng người dùng iPhone. Họ cho rằng Apple đã lừa dối người tiêu dùng (NTD) để trục lợi bằng hành vi lén lút làm giảm hiệu năng của máy nhằm mục đích buộc họ hoặc phải mua pin mới hoặc phải thay máy mới.

Tính đến cuối tháng 2/2018, ở Mỹ có tới hơn 60 vụ kiện tập thể chống lại Apple với cáo buộc hãng này cố tính làm chậm iPhone để trục lợi bất hợp pháp từ NTD. Ở các quốc gia khác như Hàn Quốc, Pháp và Israel, người sử dụng Iphone cũng tiến hành khởi kiện tập thể Apple vì cùng lý do [3].

Ở Việt Nam, ngày 10/1/2018, hai luật sư Việt Nam là Nguyễn Ngọc Hùng và Trần Mạnh Tùng từ Văn phòng luật sư Kết Nối (ngụ tại quận Long Biên, TP Hà Nội) thuộc Đoàn Luật sư Hà Nội, với tư cách người khởi kiện, đã khởi kiện Apple Inc. (trụ sở tại Mỹ), có đại diện thương nhân tại Việt Nam là Công ty TNHH Apple Việt Nam (trụ sở tại phường Bến Nghé, quận 1, TPHCM) lên Tòa án Nhân dân thành phố Hồ Chí Minh (TAND TPHCM) yêu cầu bảo vệ quyền lợi NTD mà hai ông cho rằng bị Apple Inc. vi phạm. Trong đơn khởi kiện, hai luật sư trên đề nghị tòa buộc Apple giải quyết hai yêu cầu cơ bản:

1. Có trách nhiệm đưa ra giải pháp khắc phục và chấm dứt việc gây thiệt hại cho toàn thể người tiêu dùng tại Việt Nam khi sử dụng sản phẩm điện thoại iPhone (do Apple INC sản xuất, phân phối) bị khuyết tật về kỹ thuật (cụ thể là bị suy giảm hiệu suất của điện thoại và suy giảm một số tính năng khác do sử dụng bản cập nhật hệ điều hành mới).

2. Đối với những sản phẩm đã bị lỗi, khuyết tật về kỹ thuật (cụ thể là bị suy giảm hiệu suất của điện thoại và suy giảm một số tính năng khác do sử dụng bản cập nhật hệ điều hành mới) cho các sản phẩm iPhone của toàn thể người tiêu dùng tại Việt Nam, yêu cầu Apple Inc. có trách nhiệm bồi thường thiệt hại theo quy định của pháp luật. Cụ thể: APPLE cần sửa phần mềm, hệ điều hành để điện thoại của toàn thể người tiêu dùng Việt Nam trở về đúng hiệu năng ban đầu, hoặc phải thay pin miễn phí để điện thoại của người tiêu dùng Việt Nam có hiệu năng như cũ hoặc như trước khi bị lỗi [4].

Để kêu gọi cộng đồng người dùng iPhone cùng tham gia ra khởi kiện, hai ông Hùng và Tùng đã thành lập ra một website là Batterydown.vn để những người dùng iPhone bị tác động tiêu cực từ nhà sản xuất đăng ký tham gia vụ kiện Apple tư cách đồng người khởi kiện. Tính đến ngày $27 / 2 / 2018$, website hiển thị hơn 4700 người đăng ký cùng tham gia khởi kiện Apple. [5] Trước những cáo buộc Apple trên truyền thông Việt Nam và trên thế giới về các hành vi vi phạm quyền lợi $\mathrm{NTD}$, các cơ quan quản lý Nhà nước cũng vào cuộc. Ngày 20/1/2018, Phòng Bảo vệ người tiêu dùng thuộc Cục Cạnh tranh và Bảo vệ người tiêu dùng, Bộ Công Thương đã chính thức ra "Thông báo về vụ việc Apple Inc. làm chậm tốc độ các sản phẩm điện thoại Iphone thế hệ cũ" và khuyến khích NTD có quyền lợi bị vi phạm bởi Apple gửi đơn khiếu nại trực tuyến hoặc gửi thư phản ánh đến Cục để được tư vấn, hỗ trợ giải quyết [6]. Tuy nhiên cho đến nay vẫn không có phản ứng chính thức nào từ các Hội bảo vệ người tiêu dùng TP HCM và các địa phương khác.

Vụ kiện chưa từng có tiền lệ này ở Việt Nam đã thu hút sự quan tâm đông đảo của NTD trong nước, những người hành nghề luật, các cơ quan tư pháp, người làm công tác nghiên cứu pháp luật, các cơ quan nhà nước và tổ chức xã hội có chức năng bảo vệ NTD và dư luận xã hội. Tuy vậy, kể từ ngày nộp đơn khởi kiện Apple, đã hơn 3 tháng trôi qua và sau 4 lần gặp gỡ và trao đổi giữa đại diện TAND TPHCM với những người khởi kiện [7], ngày 28/3/2018 Tòa án đã từ chối thụ lý vụ kiện với lý do hồ sơ vụ kiện không được bổ sung đúng yêu cầu [8].

Các diễn biến của vụ kiện này làm dấy lên những câu hỏi về các khía cạnh pháp lý của đơn khởi kiện Apple Inc., diễn biến tiếp theo của vụ kiện và các thách thức pháp lý mà vụ kiện đặt ra cho hệ thống pháp luật bảo vệ NTD ở Việt 
Nam mà cụ thể là quy trình thụ lý và giải quyết vụ kiện tiêu dùng theo quy định của Bộ luật Tố tụng Dân sự (BLTTDS) 2015.

\section{Những vấn đề pháp lý mà vụ kiện đặt đặt ra}

2.1. Căn cứ pháp lý của đơn khởi kiện Apple và vấn đề thu lý vu kiện

* Về tính hợp pháp của đơn khởi kiện: Trong đơn khởi kiện, hai người đồng khởi kiện là ông Hùng và ông Tùng đứng tên với tư cách NTD khởi kiện bị đơn Apple Inc. đã có hành vi xâm hại quyền lợi chính đáng của NTD bằng cách cố ý cung cấp sản phẩm khuyết tật, "gây thiệt hại cho nguoòi khởi kiện và nhũng nguời tiêu dùng trên lãnh thổ Việt Nam" [4]. Đơn kiện cũng đưa ra bằng chứng pháp lý làm cơ sở cho vụ khởi kiện chính là "Thông báo gửi khách hàng của chúng ta về pin và hiệu suất hoạt động của iPhone" của Apple phát hành ngày 20/12/2017 trên website của hãng, trong đó hãng thừa nhận đã cố ý phát hành bản cập nhật phần mềm làm chậm hoạt động của các điện thoại iPhone đời cũ mà không hề thông báo trước cho khách hàng về hậu quả của việc cập nhật này. Hậu quả là các điện thoại Iphone cập nhật phần mềm này giảm hiệu năng, người dùng phải thay pin mới để duy trì tính năng sử dụng.

Từ các cáo buộc và bằng chứng pháp lý đưa ra, việc hai ông Hùng và Tùng kiện Applevi phạm trách nhiệm của tổ chức, cá nhân kinh doanh hàng hóa, dịch vụ trong việc cung cấp thông tin cho NTD, cụ thể là vi phạm trách nhiệm "Cảnh báo khả năng hàng hóa, dịch vu có ảnh hường xấu đến sức khỏe, tính mạng, tài sản của người tiêu dùng và các biện pháp phòng ngìa" và gây thiệt hại cho người sử dụng iPhone đời cũ theo quy định tại Khoản 3 Điều 12 Luật Bảo vệ quyền lợi NTD (BVNTD) 2010 và Khoản 1 Điều 4 về quyền yêu cầu Tòa án bảo vệ quyền và lợi ích hợp pháp, BLTTDS 2015 là hoàn toàn có căn cứ pháp luật.

* Về tư cách người khởi kiện: Hai ông Hùng và Tùng là NTD bị thiệt hại do nhà sản xuất vi phạm trách nhiệm trong cung cấp hàng hóa dịch vụ, do đó có quyền khởi kiện dân sự để yêu cầu bảo vệ quyền và lợi ích hợp pháp của mình theo quy định tại Điều 186 BLTTDS 2015.

* Về thẩm quyền giải quyết vụ kiện của TANDTPHCM: Quan hệ giữa người sử dụng iPhone và Apple là quan hệ dân sự có yếu tố nước ngoài theo quy định tại Khoản 2 Điều 663 BLTTDS 2015. Bên bị kiện - Apple Inc. là thương nhân nước ngoài có trụ sở tại Mỹ nhưng lại có đại diện thương nhân là Công ty $\mathrm{TNHH}$ Apple Việt Nam đóng tại Quận 1, TPHCM. Bởi vậy, căn cứ vào quy định của Khoản 3 điều 26 về thẩm quyền giải quyết tranh chấp dân sự của Tòa án, Khoản 3 Điều 35 về loại trừ thẩm quyền của TAND cấp huyện, Điểm $a$, Điểm $b$, Khoản 1 Điều 37 về thẩm quyền của TAND cấp tỉnh và Điểm $\mathrm{a}$, Điểm $\mathrm{b}$ khoản 1 , Điều 40 về thẩm quyền của Tòa án theo sự lựa chọn của nguyên đơn, người yêu cầu quy định tại BLTTDS 2015 thì TAND TPHCM hoàn toàn có thẩm quyền giải quyết vụ kiện của hai ông Hùng và Tùng. Cụ thể hơn, nếu chấp nhận thụ lý đơn khởi kiện, TAND TPHCM sẽ giao vụ kiện cho Tòa Dân sự giải quyết.

\subsection{Tòa án trả lại đơn khởi kiện và các hậu quả pháp lý và xã hội}

Sau 2 tháng 18 ngày nghiên cứu đơn khởi kiện Apple của hai ông Hùng và Tùng và bốn lần trì hoãn trả lời, TAND TPHCM đã quyết định trả lại đơn khởi kiện vì hồ sơ không hợp lệ [8]. Điều này dấy lên câu hỏi về tính phù hợp với quy định của pháp luật và các diễn biến tiếp theo của vụ kiện.

Đơn khởi kiện gửi TAND TP HCM và Giấy xác nhận đã nhận đơn khởi kiện của hai ông Hùng và Tùng đã được scan đưa lên website Baterydown.vn cho thấy đơn này đáp ứng đầy đủ các yêu cầu về nội dung theo quy định tại Khoản 4 Điều 189, BLTTDS 2015. Theo phản ánh, kể từ ngày khởi kiện $10 / 1 / 2018$ đến ngày 28/3/2018 (2 tháng và 18 ngày), trong suốt thời gian xử lý đơn kiện, đại diện Tòa án đã có bốn lần gặp gỡ và trao đồi với hai người khởi kiện rằng vụ kiện rất phức tạp, cần thêm thời gian 
nghiên cứu và yêu cầu bổ sung thêm bằng chứng pháp lý như cần bản dịch sang tiếng Việt có công chứng các tài liệu như Thông báo của Apple Inc. gửi khách hàng và các tài liệu tiếng Anh khác làm minh chứng trong hồ sơ vụ kiện [9]. Ngày 13/3/2018 (lần gặp thứ ba) hai ông Hùng và Tùng đã tuân thủ đầy đủ các yêu cầu này thể hiện trong bút lưu của Tòa án tại Giấy xác nhận đã nhận đơn khởi kiện [7]. Tòa án tiếp tục khất câu trả lời đến ngày $23 / 3 / 2018$, nhưng đến 28/3/2018 mới chính thức trả lời không thụ lý vụ kiện vì người khởi kiện không sửa đổi, bổ sung đơn khởi kiện theo yêu cầu của Tòa án quy định điểm e Khoản 1 Điều 192 BLTTDS [8].

Có thể thấy, trong tác nghiệp, TAND TPHCM đã không nhất quán trong nội dung trao đổi thông tin với người khởi kiện về các lý do trì hoãn việc ra quyết xử lý vụ kiện và lý do được viện dẫn làm căn cứ để trả lại đơn kiện. Chưa kể chính việc Tòa chủ động trì hoãn trả lời đơn kiện tới bốn lần là nguyên nhân dẫn đến vi phạm thời hiệu xử lý đơn khởi kiện quy định tại Khoản 2 và 3 Điều 191 của BLTTDS 2015. Các diễn biến này cho thấy TAND TPHCM chưa tôn trọng nguyên tắc về thời hạn xử lý đơn kiện và vi phạm quyền được trả lời đúng hạn của người khởi kiện. Việc trả lại đơn kiện sẽ làm nảy sinh những hậu quả pháp lý sau: (1) Tòa án phải trả lời bằng văn bản nêu rõ lý do trả lại đơn khởi kiện cho Viện Kiểm sát cùng cấp và các đương sự và (2) Người khởi kiện có thể gửi đơn khiếu nại đến Tòa án, Viện kiểm sát có quyền kiến nghị với Tòa án về quyết định trả lại đơn khởi kiện.

Về mặt dư luận xã hội, cách thức TAND TPHCM xử lý đơn khởi kiện Apple của hai ông Hùng và Tùng làm dấy lên những băn khoăn về lý do thực sự đằng sau quyết định trả lại đơn khởi kiện: do vụ kiện đặt ra quá nhiều thách thức không giải quyết nổi cho ngành tòa án trong áp dụng luật tố tụng dân sự hiện hành hay do Tòa án chưa thực sự quan tâm đến lẽ công bằng và chức năng bảo vệ NTD Việt Nam?

\section{Những thách thức pháp lý vụ kiện đặt ra cho Tòa án và những người khởi kiện}

Vụ kiện chưa từng có tiền lệ này sẽ mang lại những thách thức pháp lý lớn cho TAND TPHCM nói riêng và cho toàn bộ hệ thống Tòa án Việt Nam trong việc áp dụng các quy định của pháp luật tố tụng dân sự vào giải quyết.

\subsection{Các rắc rối tù thủ tục tố tụng trong thu lý đơn khởi kiện và xét xư vu án}

Vụ án có một số lượng rất lớn người muốn cùng tham gia khởi kiện. Trong vụ kiện, thông qua website Batterydown.vn, hai ông Hùng và Tùng đã vận động được hơn 4.700 người cùng tham gia khởi kiện với hai ông qua hành vi đăng ký vào website. Giả sử số người có nguyện vọng tham gia khởi kiện này là có thực và có đầy đủ tư cách khởi kiện, ${ }^{1}$ Tòa án cần áp dụng pháp luật pháp hiện hành thế nào để giải quyết vụ kiện hy hữu này.

Về cách thức thu lý vu kiện: Hiện tại BLTTDS 2015 của Việt Nam không có quy định về cơ chế "khởi kiện tập thể" (Class action civil lawsuit) do đó chỉ có các lựa chọn hoặc khởi kiện trực tiếp hoặc khởi kiện thông qua đại diện là cá nhân, tô chức hợp pháp khác theo quy định tại Điều 186 về Quyền khởi kiện vụ án. Như vậy, Tòa có thể yêu cầu ông Hùng, ông Tùng và hơn 4.700 người đăng ký tham gia khởi kiện Apple lựa chọn một trong bốn phương thức dưới đây.

(1) Tòa án thụ lý riêng lẻ đơn khởi kiện của hai ông Hùng và Tùng hơn 4700 người khởi kiện khác, sau đó nhập thành một vụ án dân sự lớn để xét xử theo quy định tại Khoản 1 và khoản 2 điều 42 của BLTTDS 2015. Phương thức này, một mặt, sẽ tạo ta một số lượng khổng lồ các vụ kiện riêng lẻ, tạo áp lực lên Tòa án trong việc ra quyết định thụ lý và đưa ra xét

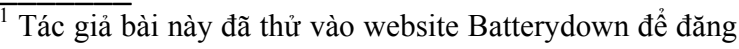
ký tham gia vụ kiện với những thông tin tự tạo ra nhưng ngay lập tức được chấp nhận mà không có khâu kiểm chứng, xác thực thông tin nào. Điều này làm dấy lên câu hỏi về tính xác thực của số lượng hơn 4.700 người sử dụng iPhone muốn tham gia vụ kiện mà website phản ánh.
} 
xử đối với những vụ kiện riêng rẽ nhưng lại có nội dung và yêu cầu tương tự. Mặt khác, cách này cũng có thể làm cho một số lượng không nhỏ NTD nhụt chí, rút đơn khởi kiện và chấp nhận một thực tế rằng mình đã bị Apple xâm phạm quyền lợi. Phần lớn NTD Việt Nam có tâm lý phổ biến là sợ đi kiện và tham gia tố tụng cho dù biết quyền lợi chính đáng của mình đang bị thương nhân vi phạm.

(2) Để có tư cách đồng nguyên đơn với hai ông Hùng và Tùng trong cùng vụ kiện, những người này phải cùng ký tên trong đơn khởi kiện của hai ông Hùng và Tùng và gửi lên Tòa án yêu cầu giải quyết vụ kiện. Cách làm này khó có thể thực hiện bởi lẽ sẽ gây ra rất nhiều khó khăn và chi phí cho việc thu thập chữ ký của một số lượng khổng lồ những người dùng iPhonesinh sống, làm việcở mọi miền đất nước.

(3) Theo quy định tại Khoản 3 và 4 Điều 187 về Quyền khởi kiện vụ án dân sự, hai ông Hùng và Tùng và những người sử dụng iPhone đã đăng ký cùng tham gia vụ kiện Apple vừa phải tự mình làm đơn khởi kiện gửi $\mathrm{TAND}$ TPHCM vừa phải làm hợp đồng ủy quyền cho một luật sư/văn phòng luật sư hay tổ chức bảo vệ quyền lợi người tiêu dùng tham gia tố tụng và đại diện và bảo vệ cho quyền lợi. Tuy nhiên, trong quá trình xét xử Tòa án vẫn phải xem xét từng yêu cầu độc lập của những người khởi kiện thông qua đại diện này.

(4) Những người muốn tham gia vụ kiện Apple Inc. của hai ông Hùng và Tùng sẽ tham gia vụ kiện với tư cách người có quyền lợi nghĩa vụ liên quan,"là nguoòi tuy không khởi kiện, không bi kiện, nhung việc giải quyết vu án dân sự có liên quan đến quyền lợi, nghĩa vu của ho nên ho được tụ minh đề nghi hoặc các đương sư khác đề nghi và được tòa án chấp nhận đưa ho vào tham gia tố tụng với tur cách là người có quyền lợi, nghĩa vu liên quan."theo Khoản 4 Điều 68 BLTTDS 2015. Làm theo phương thức này, tính áp lực, tầm ảnh hưởng của vụ kiện lên nhà sản xuất sẽ bị suy yếu. Người sử dụng iPhone là "người tiêu dùng" theo quy định tại Khoản 1 Điều 3 của Luật BVNTD 2010 đã trở thành "người có quyền lợi, nghĩa vụ có liên quan". Nếu thụ lý vụ kiện theo cách này, vô hình chung, tòa án đã khuyến khích việc đánh tráo khái niệm và làm NTD nhụt chí, không muốn lên tiếng bảo vệ quyền lợi chính đáng của mình.

Tóm lại, trong số bốn phương án để thụ lý và giải quyết vụ kiện kể trên, phương án thứ ba là khả thi nhất. Tuy nhiên theo quy định của pháp luật hiện hành việc giải quyết vụ kiện vẫn rất phức tạp bởi lẽ nó không loại trừ được hoạt động xem xét từng nội dung và yêu cầu khiếu kiện riêng rẽ của một số lượng khổng lồ các nguyên đơn. Chưa kể đến các hoạt động ủy quyền tham gia tố tụng riêng lẻ, phức tạp mà hàng loạt người khởi kiện phải thực hiện.

\subsection{Về nghĩa vu chứng minh thiệt hại và trách nhiệm chứng minh của nguyên đơn và bị đơn}

Thông lệ quốc tế cho thấy việc giải quyết những vụ kiện của NTD đối với thương nhân cung cấp hàng hóa dịch vụ không đơn giản. Cả trên lý thuyết và thực tiễn đều chứng minh được rằng trong giao dịch với thương nhân, người tiêu dùng luôn ở vị trí yếu thế bởi "tính bất cân xứng về thông tin" (Asymmetric information); hầu hết các thông tin về hàng hóa dịch vụ đều do nhà sản xuất cung cấp và không dễ gì kiểm chứng được, vì vậy NTD dễ bị lạm dụng thông qua những hành vi thương mại không công bằng của nhà sản xuất [10]. Chính vì vậy luật bảo vệ NTD của hầu hết các quốc gia trên thế giới đều có những quy định mang tính "thiên vị”, tạo điều kiện thuận lợi cho NTD trong giải quyết tranh chấp. Điều 42 Luật BVNTD 2010 và Điểm $\mathrm{a}$, Khoản 1 Điều 91 BLTTDS 2015 quy định rằng NTD có nghĩa vụ chứng minh thiệt hại của mình do hàng hóa dịch vụ gây ra; tổ chức, cá nhân kinh doanh hàng hóa, dịch vụ bị kiện có nghĩa vụ chứng minh mình không có lỗi gây ra thiệt hại cho NTD.

Việc chứng minh thiệt hại của NTD trong vụ kiện này dù không đơn giản nhưng không phải là không làm được và có cả hai mặt thuận lợi và khó khăn.

Mặt thuận lợi: Về pháp lý, Apple Inc. đã thừa nhận chính thức việc cố tình phát hành bản 
cập nhật các hệ điều hành cập nhật iOS 10.2.1 cho các phiên bản iPhone 6 và hệ điều hành iOS 11.2 cho các phiên bản iPhone 7 để làm giảm hiệu năng của pin điện thoại mà không hề công bố cho khách hàng biết trước. Dễ dàng thấy hành vi này đã vi phạm quyền lợi NTD ở hai góc độ: (1) Vi phạm quyền được thông tin về hàng hóa sản phẩm theo quy định tại Điều 13 Luật BVNTD khiến cho NTD không thực hiện được quyền lựa chọn và đưa ra quyết định phù hợp và (2) Việc che dấu hậu quả của việc cập nhật hệ điều hành đã gây ra thiệt hại cho NTD. Hậu quả là những NTD đã cập nhật hệ điều hành phải đứng trước hai lựa chọn cùng gây ra thiệt hại vật chất là hoặc phải bỏ ra một số tiền thay pin mới do Apple cung cấp hoặc vứt bỏ máy để mua điện thoại mới.

Thêm vào đó, đơn khởi kiện đã cáo buộc Apple chủ ý phát hành bản cập nhật hệ điều hành cho các iPhone thế hệ cũ nhằm trục lợi NTD Việt Nam là có những căn cứ nhất định bởi lẽ Apple gây ra thiệt hại cho NTD nhưng lại không bồi thường thiệt hại mà vẫn tiếp tục bán pin cho NTD đề thay thế, cho dù đã có động thái giảm giá bán pin. Về nguyên tắc, theo quy định tại Điều 22 về trách nhiệm thu hồi hàng hóa có khuyết tật và Điều 23 về̀ trách nhiệm bồi thường thiệt hại do hàng hóa có khuyết tật gây ra, Apple phải có trách nhiệm bồi thường toàn bộ thiệt hại phát sinh cho người sử dụng Iphone như bồi hoàn tiền thay pin mới và các chi phí có liên quan đến việc thay pin, sửa máy... và cả những thiệt hại gián tiếp gây ra do điện thoại hoạt động chậm không đáp ứng yêu cầu thông tin, liên lạc. Có lẽ do chứng minh các thiệt hại gián tiếp không đơn giản nên phạm vi yêu cầu trong đơn khởi kiện của hai ông Hùng và Tùng là khá khiêm tốn, chỉ bao gồm cung cấp các giải pháp khắc phục hiện tượng máy chậm (đổi, sửa máy điện thoại), chấm dứt thiệt hại gây ra và bồi thường thiệt hại bao gồm chi phí cho việc thay pin, sửa máy và các chi phí có liên quan trực tiếp khác.

Mặt khó khăn: Dù Apple đã thừa nhận lỗi nhưng những người khởi kiện vẫn phải chứng minh thiệt hại gây ra cho người dùng iPhone
Việt Nam. Các tài liệu minh chứng liên quan đến các vụ khởi kiện tập thể đối với Apple ở Mỹ và ở các nước khác chỉ có giá trị tham khảo, không có giá trị chứng cứ trong vụ kiện này [4]. Thông thường, việc chứng minh các thiệt hại này NTD khó tự thực hiện được, mà cần sự hỗ trợ trong phân tích, đánh giá từ các chuyên gia công nghệ cao và các chuyên gia kinh tế. Chưa kể việc chứng minh thiệt hại có thể kéo theo những chi phí đáng kể cho người khởi kiện.

\subsection{Vấn đề thi hành án trong tuoong lai}

Giả thiết rằng TAND TPHCM thụ lý và xét xử vụ kiện và ra phán quyết có lợi nghiêng về phía các nguyên đơn, việc yêu cầu Apple Inc. tại Mỹ thi hành án bản án có hiệu lực của Tòa án Việt Nam là một điều không dễ dàng. Việc này đòi hỏi rất nhiều thủ tục tư pháp quốc tế và ngoại giao giữa hai bên. Do phạm vi có hạn của bài viết nên vấn đề này sẽ được bàn tới như một chủ đề riêng trong một nghiên cứu khác.

\section{Bình luận và một số gọii ý để thụ lý và xét xử các vụ kiện tương tự tại Việt Nam}

Từ các thách thức pháp lý đặt ra đối với những người khởi kiện Apple ở Việt Nam, TAND TPHCM nói riêng và hệ thống tòa án nói chung, có thể nhận thấy rằng những vấn đề pháp lý phức tạp không đến từ nội dung và yêu cầu pháp lý của người khởi kiện mà đến từ chính các quy định hiện hành về thủ tục thụ lý và giải quyết các vụ kiện dân sự mà có nhiều người cùng khởi kiện một cá nhân hay tổ chức.

Ngoài những lý do khiến tòa án lúng túng, trì hoãn nhiều lần trong việc đưa ra quyết định thụ lý hay trả lại đơn khởi kiện như vụ kiện phức tạp, quá đông người muốn tham gia với tư cách nguyên đơn, chưa từng có tiền lệ trong ngành tòa án, nguyên nhân nằm sâu bên trong là các quy định của pháp luật tố tụng dân sự Việt Nam hiện tại không còn đáp ứng được các yêu cầu về thụ lý và xét xử những vụ kiện tiêu dùng lớn mang tính tập thể như vụ kiện này. 
Luật Tố tụng dân sự Việt Nam không có quy định về những vụ "kiện tập thể" để giải quyết các tranh chấp tư, trong đó có nhiều người cùng khởi kiện một người. Trong khi đó, trên thế giới kiện tập thể được áp dụng rất phổ biến trong giải quyết các tranh chấp lao động và tiêu dùng. Theo pháp luật tố tụng dân sự các nước như Mỹ, châu Âu và các nước ASEAN như Singapore, Malaysia, Philipinnes, Thái Lan, Indonesia, các vụ kiện trong đó có nhiều người đứng đơn kiện một tổ chức hoặc cá nhân được tòa án coi là vụ kiện tập thể và được thụ lý và xét xử khi thỏa mãn các tiêu chí cơ bản sau: (1) Nhóm người tham gia khởi kiện quá lớn đến mức việc giải quyết các vụ kiện riêng rẽ là quá phức tạp và không thể thực hiện được, (2) Phải có những vấn đề pháp lý và thực tiễn chung cho cả nhóm, (3) Các yêu cầu hoặc lời biện hộ của người đại diện đứng ra khởi kiện phải phù hợp với lợi ích của nhóm người tham gia và (4) Người đại diện khởi kiện phải bảo vệ một cách thích hợp lợi ích của cả nhóm [11].

Từ các tiêu chí của một "vụ kiện tập thể nói trên" theo thông lệ quốc tế, có thể thấy rằng vụ kiện Apple của NTD Việt Nam hoàn toàn đáp ứng được các yêu cầu về tính quy mô, bản chất và nội dung các yêu cầu pháp lý của một vụ kiện tập thể. Nếu có cơ chế khởi kiện tập thể, TAND TPHCM sẽ dễ dàng tháo bỏ được những rào cản về thủ tục tố tụng hiện hành để giải quyết vụ kiện Apple một cách triệt để, bảo vệ hiệu quả quyền lợi của NTD Việt Nam. Mặc dù hiện tại, vụ kiện bị TAND TPHCM từ chối xét xử nhưng dưới góc độ tư pháp và góc độ xã hội, vụ kiện đã mang lại các ý nghĩa tích cực, cụ thể:

Thư nhất, vụ kiện Apple tạo ra một tiền lệ tích cực khuyến khích giới hành nghề luật và NTD Việt Nam mạnh dạn hơn trong việc bảo vệ quyền lợi chính đáng trong quan hệ tiêu dùng với những nhà sản xuất có thế lực trên thế giới. Vụ kiện cũng đặt ra nhu cầu thúc bách về cải cách tư pháp, sửa đổi BLTTDS hiện hành và trau dồi năng lực cho thẩm phán để có một cơ chế khởi kiện tập phù hợp với yêu cầu thụ lý và giải quyết hiệu quả đối với tranh chấp tiêu dùng tập thể. Cơ chế khởi kiện tập thể sẽ giúp Tòa án giảm tải về khối lượng công việc hành chính tư pháp và tập trung vào chuyên môn xét xử.

Thư hai, vụ kiện tập thể sẽ giúp tiết kiệm thời gian, công sức và chi phí các đồng nguyên đơn bởi lẽ họ không phải tự mình tham gia tố tụng, tự chứng minh thiệt hại, tự tạm ứng án phí một cách riêng lẻ. Đặc biệt nghĩa vụ chứng minh của NTD sẽ nhận được sự hỗ trợ, tham gia chuyên nghiệp tích cực các công ty luật đại diện cho những người khởi kiện, không còn thách thức lớn nhất đối với NTD Việt Nam trong vụ kiện này.

Thư $b a$, vụ kiện tập thể sẽ gây ra một áp lực lớn về nỗi lo sợ mất đi một thị trường đang trên đà tăng trưởng đối với Apple Inc. và cả Công ty TNHH Apple Việt Nam. Đối với các thương nhân, không có sức ép nào buộc họ phải điều chỉnh hành vi kinh doanh lớn hơn là thái độ phản đối và tẩy chay hàng hóa dịch vụ từ phía NTD. Nhiều khả năng sau khi vụ kiện được thụ lý, Apple Inc. sẽ phải tìm cách hòa giải với NTD trước khi có phán quyết của Tòa án.

Thứ tu, vụ kiện tập thể sẽ tạo ra sự ủng hộ rộng rãi trong dư luận xã hội, khiến các cơ quan, tổ chức xã hội có chức năng bảo vệ NTD như Cục Cạnh tranh và Bảo vệ người tiêu dùng, các hội bảo vệ NTD có trách nhiệm hơn và cùng vào cuộc và hỗ trợ những người khởi kiện.

Tóm lại, việc áp dụng cơ chế khởi kiện tập thể để thụ lý và đưa ra xét xử vụ kiện Apple sẽ khắc phục được tất cả những trở ngại pháp lý đã đề cập và phân tích ở trên. Trong một nghiên cứu trước đó về cơ chế khởi kiện tập thể bảo vệ NTD trong pháp luật một số nước ASEAN, tác giả cũng đã đưa ra các khuyến nghị về bổ sung cơ chế khởi kiện tập thể vào BLTTDS 2015 và Luật BVNTD 2010 để giải quyết hiệu quả các tranh chấp tiêu dùng có quy mô lớn và cảnh tỉnh nhà cung cấp hành hóa dịch vụ khi họ có hành vi xâm phạm quyền lợi người tiêu dùng [11].

Rõ ràng rằng vụ kiện Apple đang đóng vai trò tiên phong trong việc thúc đẩy hệ cơ quan lập pháp và tư pháp Việt Nam tìm ra phương thức hiệu quả hơn để giải quyết tranh chấp tiêu dùng ở quy mô lớn. Với xu thế gia nhập các 
hiệp định tự do thương mại thế hệ mới, các quan hệ thương mại - tiêu dùng sẽ ngày càng phát triển và sôi động; có thể nhìn thấy trong tương lai gần số lượng các vụ kiện có số đông NTD khởi kiện các pháp nhân thương mại cung cấp hàng hóa dịch vụ trong các lĩnh vực như mua bán nhà chung cư, các dịch vụ như điện, nước, tín dụng, viễn thông... sẽ ngày càng tăng. Không có cơ chế khởi kiện tập thể, NTD sẽ thiệt thòi, ngành tòa án cũng sẽ không có cơ hội mài giũa chuyên môn, thực thi công lý.

Không thể phủ nhận rằng nhu cầu khởi kiện tập thể để bảo vệ quyền lợi NTD là hoàn toàn chính đáng trong nền tư pháp hiện đại. Điều này cũng cho thấy với các quy định phức tạp, nhiều tầng nấc của BLTTDS hiện hành về thụ lý và xét xử những vụ kiện có nhiều người cùng khởi kiện đối với một tổ chức, cá nhân đã trở nên lạc hậu, không còn đáp ứng thực tiễn phức tạp và sôi động của nền kinh tế thị trường. Để khắc phục các hạn chế này, các nhà làm luật nên nhanh chóng tiếp cận các thông lệ quốc tế và trong khu vực ASEAN về kiện tập thể để nghiên cứu, học tập kinh nghiệm nhằm bổ sung khái niệm kiện tập thể, các điều kiện khởi kiện và quy trình, thủ tục giải quyết vụ kiện tập thể vào $\mathrm{BLTTDS}$ hiện hành để bảo đảm rằng quy trình tố tụng thực sự bảo vệ NTD một cách hiệu quả, bảo vệ nền thương mại công bằng và sự phát triển lành mạnh của nền kinh tế thị trường.

\section{Kết luận}

Mặc dù còn nhiều tranh luận về tính khả thi của vụ kiện Apple của NTD Việt Nam, nhưng không thể phủ nhận rằng vụ kiện này đã mở đầu cho xu hướng khởi kiện tập thể trong tranh chấp tiêu dùng - một xu hướng tất yếu, một quy trình tư pháp bắt buộc phải có trong nền kinh tế thị trường, không còn là một tình huống giả định trong hoạt động tư pháp nước ta. Một cách khách quan, có thể thấy các quy định hiện tại về thụ lý và xét xử với các vụ kiện có nhiều nguyên đơn cũng kiện một bị đơn, quy định về nhập các vụ án dân sự, các yêu cầu khởi kiện đối với cùng một bị đơn đã đặt được những nền tảng pháp lý đầu tiên cho kiện tập thể trong tố tụng dân sự Việt Nam. Tuy không còn sớm, nhưng đây cũng là những khởi đầu mang lại những thuận lợi nhất định cho các nhà làm luật trong xây dựng quy trình khởi kiện tập thể ở Việt Nam.

\section{Tài liệu tham khảo}

[1] Jordan Buie, Meet Mt. Juliet teen who showed how Apple slows down old iPhones on Reddit, USA TODAY NETWORK - Tennessee December 22, 2017 inhttps://www.tennessean.com/story/news/2017/1 2/22/mount-juliet-teens-iphone-discovery-goesviral-leads-lawsuits-against-apple/976745001/ (truy cập 20/1/2018).

[2] Apple Inc., A Message to Our Customers about iPhone Batteries and Performance, in https://www.apple.com/lae/iphone-battery-andperformance/ December 28,2017(truy cập 01/3/2018).

[3] Yoni Heisler, There are now almost 60 classaction lawsuits against Apple for secretly throttling iPhones tạ http://bgr.com/2018/02/26/iphone-battery-classaction-lawsuits-consolidation/ (updated 26 February 2018).

[4] Văn phòng Luật sư Kết Nối, http://batterydown.vn/\#vebatterydown (truy cập 17/3/2018).

[5] Phan Thương, Người Việt kiện Hãng Apple, được không? Báo Thanh niên Điện tử sốra 04/3/2018 tại https://thanhnien.vn/thoi-su/nguoiviet-kien-hang-apple-duoc-khong938358.html(truy cập 19/3/2018).

[6] Cục Canh tranh và Bảo vệ người tiêu dùng, Thông báo về vu viẹc Apple Inc. làm chậm tốc độ các sản phẩm điện thoại Iphone thế hệ cũngày 20-01

2018, tạihttp://www.vca.gov.vn/chitietbvntd.aspx ?ID=3859\&Cate_ID=436(cập nhật 20/3/2018).

[7] Quốc Chiến, Vu kiện Apple làm chậm iPhone: Tòa án khất hẹn lần thứ 4,Báo Người Lao động điện tử, số ra 18/3/2018 tại https://nld.com.vn/phap-luat/vu-kien-apple-lamcham-iphone-toa-an-khat-hen-lan-thu-420180318122905218.htm (truy cập 20/3/2018).

[8] Hải Duyên, Tòa tù chối thu lý vu kiện Apple làm chậm iPhone, Báo điện tử VNExpress ngày 28/3/2018 tại https://vnexpress.net/tin-tuc/phap- 
luat/toa-tu-choi-thu-ly-vu-kien-apple-lam-chamiphone-3729064.html (truy cập 28/3/2018).

[9] Quốc Chiến, Tòa cần thêm thời gian xem xét vu luật su kiện Apple, Báo Người Lao động điện tử tại https://nld.com.vn/phap-luat/toa-can-themthoi-gian-xem-xet-vu-luat-su-kien-apple20180122194958179.htmngày 22/01/2018 (cập nhật 15/3/2018).
[10] Becher, S.I., Asymmetric Information in Consumer Contracts: The Challenge that is Yet to be Met, American Business Law Journal, 2008,. Vol. 45, tr.11-13.

[11] Phan Thị Thanh Thủy, Kiện tập thể trong giải quyết tranh chấp tiêu dùng ở một số nước ASEAN và nhũng gơi ý cho Việt Nam, Tạp chí Nhà nước và Pháp Luật,. 1(357)/2018, tr. 47-49.

\title{
Discussing the Trend of Class Action in Consumer Dispute Settlement Based on the Lawsuit Against Apple over Slowing Down iPhones in Vietnam
}

\author{
Phan Thi Thanh Thuy \\ VNU School of Law, 144 Xuan Thuy, Cau Giay, Hanoi, Vietnam
}

\begin{abstract}
On January 10, 2018, two Vietnamese lawyers representing a large number of consumers across the country instituted a civil case against Apple Inc. to the People's Court of Ho Chi Minh City for the reason that this corporation violated the manufacturer's responsibility and caused damage to the users of iPhones in Vietnam. The lawsuit has been quickly paid attention to by legal practitioners, scholars and public opinion. This article analyzes and points out the legal challenges that the lawsuit posed to the court system and the indispensable trend toward class action lawsuit in the Vietnamese civil procedure law.
\end{abstract}

Keywords: Consumer, institute a civil case, class action, iPhone, Apple, Vietnam. 